\title{
Microsatellite Markers in Conservation and Management of Wildlife: a Brief Perspective
}

\author{
Kush Shrivastava ${ }^{1}$, Rebeka Sinha ${ }^{2}$, Shweta Singh Chauhan ${ }^{3}$ \\ and Mohan Singh Thakur ${ }^{1,4} *$
}

${ }^{I}$ Division of Animal Genetics, ICAR - Indian Veterinary Research Institute, Izatnagar, Bareilly, UP., India

${ }^{2}$ Dairy Cattle Breeding Division, ICAR - National Dairy Research Institute, Karnal, Haryana, India

${ }^{3}$ Department of Veterinary Biochemistry, College of Veterinary Science and A.H., Jabalpur, M.P., India

${ }^{4}$ Department of Animal Genetics and Breeding, College of Veterinary Science and A.H., NDVSU, Jabalpur, M.P., India

*Corresponding author

\section{A B S T R A C T}

Keywords

Microsatellite,

Conservation genetics,

Wildlife, Molecular

markers, Non-invasive genotyping

Article Info

Accepted:

17 June 2018

Available Online:

10 July 2018

\section{Introduction}

Microsatellites or simple sequence repeats (SSRs) are tandemly repeated motifs of $1-6$ bases found in all prokaryotic and eukaryotic genomes. They are ubiquitously present within the genomes and are usually characterized by a high degree of length polymorphism. Microsatellites are valuable tools for genome mapping in many organisms (Knapik et al., 1998), however, they are also widely used for ancient and forensic DNA studies, in population genetics and conservation/ management of biological species (Jarne and Lagoda, 1996). The repeat motifs of microsatellites are usually up to six base pair long and are tandemly repeated and a single motif is usually arranged in repeating units in 
head to tail manner without interruptions. These tandemly repeating di- or tri- nucleotide bases create polymorphism by varying the number of repeat unit and are shown to be polymorphic in almost all eukaryotic organisms (Litt and Luty, 1989). Frequency of their occurrence, co-dominant nature, polymorphism and distribution in genome make them an excellent marker for mapping studies (Luty et al., 1990). Furthermore, the property of being multiplexed and automatization provides new areas where these markers can be potentially applied in large sample sizes. From past decade the use of microsatellites in natural populations has been increasing tremendously, and they have been used for analysis of population structure (Arora and Bhatia, 2004) and dispersal patterns (Wimmer et al., 2002), estimation of genetic variability and inbreeding (Mateus et al., 2004), evaluation of paternity to maintain pedigree records (Luikart et al., 1999), for tracking alleles through a population (Arranz et al., 1998) and individual identity and estimation of degree of relatedness between populations or pairs of individuals (Maudet $e t$ al., 2002). The increment in use of microsatellite markers for population level studies have been due to the fact that they are randomly found distributed throughout the genome, occurs in non-coding part, neutral, highly polymorphic within and between breed/ species, co-dominant in nature and a relatively small mount of DNA is required for genotyping as it is PCR based. The genomic DNA for microsatellite genotyping can be obtained from tissue or minute quantities of blood, from shed hairs, epithelial sloughing in saliva (Inoue et al., 2007) urine (Valiere and Taberlet, 2000) or faeces (Brinkman et al., 2011; Shrivastava et al., 2013). The loci are amplified by PCR and resolved in denaturing PAGE or alternatively, the primers are sometimes fluorescently labelled, and the allele sizing is done by automatic fluorescent scanner to produce peaks at different alleles.
Because alleles vary in the number of repeats of the microsatellite motif, heterozygous individuals will show two PCR product bands, while homozygote will only display a single band.

Application of molecular methods in estimation of genetic diversity of natural populations, species identification in animal forensics provides advantage of being reproducible and accurate. The use of genetic techniques in conservation of wild natural populations is in diversity analysis and it aims in estimating the relatedness between individuals in a population to design a proper mating plan to minimize inbreeding and reduce incestuous mating in captive breeding programms (Frankham et al., 2002). Populations having lower genetic diversity and elevated levels of inbreeding are relatively higher risk of extinction (Saccheri et al., 1998). Russello and Amato (2004) has emphasized that "assessment and preservation of biodiversity of wild populations is crucially important to minimize the loss of initial genetic variation as a consequence of inbreeding". This brief perspective article will focus on the application of microsatellites in wildlife conservation and decision making and the challenges faced in the application of this technique in natural populations.

\section{Estimation of genetic diversity and inbreeding}

One of the most potential roles of microsatellite markers is in genetic diversity and inbreeding analysis. Inbreeding in wild populations has been known to occur and its consequences have been an issue of debate. Ralls et al., (1988) used the data of forty captive populations from 38 species and showed average increase in mortality of $33 \%$ inbred mating, they also suggested that in natural population the total cost of inbreeding depression in wild species may be much higher and may have substantial evolutionary 
consequences (Ralls et al., 1988; Crnokrak and Roff, 1999). Later on, Crnokrak and Roff (1999) showed that cost on inbreeding in wild species was much higher in natural populations than in captive bred populations and fitness traits exhibited moderate to high levels of inbreeding depression under natural conditions. Slate et al.(2000) used nine microsatellite markers in red deer population (Cervus elaphus) to estimate the effect of inbreeding depression on lifetime breeding success in natural wild population. They showed that heterozygosity was positively correlated with male and female life time breeding success in targeted red deer population (Slate et al., 2000). Inbreeding effects the health and lifetime parameters in wild species. Charpentier et al., (2008) showed the effect of inbreeding on captively bred ring-tailed lemurs housed under semi natural conditions. Genomic DNA was obtained from blood and tissues and the animals were genotyped at $10 \quad-15$ microsatellite loci developed from bamboo lemur and eastern lesser bamboo lemur. It was shown that genetic diversity affects the fitness related traits including burden of parasites (some expressing immunocompetence), it was also shown that inbred lemurs are likely to die earlier due to diseases as compared to the outbred ones (Charpentier et al., 2008). Liberg et al., (2005) discovered a severe inbreeding depression in wild wolf population using 32 autosomal microsatellite loci.The question of number of loci than must be used for accurate assessment of inbreeding depression was addressed by Slate and Pemberton (2002), that showed that power to detect heterozygosityfitness association is low when ten or lesser number of markers are used. However, they also concluded that molecular methods can not always be used to disregard the presence of inbreeding in populations and they may not detect all cases of inbreeding depressions (Slate and Pemberton, 2002). O'Grady et al., (2006) estimated the risk of extension due to increased levels of inbreeding using simulation study. They concluded that median time of extinction across species is increased with increment in inbreeding or with inbreeding depression. Inbreeding depression lowers the population size that increases the probability of extinction. Thus, it becomes necessary to ascertain and give emphasis to inbreeding levels during captive mating programmes and introduction/ re-introduction of species. The other important estimates that can be obtained by application of microsatellites is the heterozygosity, genetic diversity or distance or estimation of hybridisation in natural populations. Arif et al., (2010) utilized seven microsatellite loci on 24 Arabian oryx to assess genetic diversity in captive bred population. They found high level of genetic diversity within the population with average gene flow ranging from 0.204 to 0.424 and emphasized on the use of marker related genetic diversity indices in management of captive breeding programme (Arif et al., 2010). Diversity analysis has been a mainframe in formulating mating plan and management of wild animal species either in captive areas or semi captive or natural habitats, Zidek et al., (2008) performed biodiversity analysis using nine microsatellite loci in two different populations of deer and found that majority of genetic variation (89.1 $\%)$ was due to differences among individuals and only $11.9 \%$ was due to differentiation among the origin of animals, Ruiz-Garcia et al., (2006) has reported high level of genetic diversity in Columbian jaguar population and reported no bottleneck effects in the population overall. A significant finding with managemental perspective was reported by Valvo et al., (2009). They found out genetic sub-structuring in Red deer (Capreolus capreolus) in provinces of Belluno and Trento and pointed out that the ecological sub divisions of the populations did not coincide with the administrative sub-divisions of the province that are used for management of the 
population underscoring the usefulness of genetic estimated of population structure in managemental decisions (Valvo et al., 2009).

\section{Parentage and hybridization}

Another important aspect of application of these markers, which requires a separate mention is in parentage analysis and estimation of hybridisation in wild populations. Haanes et al., (2005) identified a panel of microsatellite markers, for Norwegian red deer, that can be used for parentage analysis in large populations when one parent is known which can be effectively used in captive bred individuals. A significant application was reported by DeYoung et al., (2002), which showed multiple paternity in white tailed deer using microsatellite markers. They reported the first ever case of multiple paternity for single ungulate litter that can have implications on reproductive biology of the species and their management strategies (DeYoung et al., 2002). Zsolnai et al., (2009) have developed eight plex microsatellite PCR for parentage determination and control in deer (Red deer and fallow deer). Similarly, microsatellite markers have been developed for plateau pika (Ochotona curzoniae) (Li et al., 2009) and have been shown to be 99.999 $\%$ effective in determination of parentage in plateau pika (Li et al., 2010). Hybridisation and cross amplification of microsatellites from different related species have also been found useful, in study of forensics or identification or in estimation of introgression. Cross amplification is substantially an important aspect as some endangered / cryptic species are hard to find and hence, isolation and development of novel microsatellite markers in such species will be quite difficult. Such cross amplifications have been reported between woolly monkeys and new world primates (DiFore and Fleischer, 2004), cattle and wild gaur (Nguyen et al., 2007), ungulates and Pampas deer (Cosse et al., 2007) etc. A significant study that deserves separate mention was of Mantellatto et al., (2010), they used microsatellite loci from Reindeer (Rangifer tarandus), Red deer (Cervus elaphus), Chital or spotted deer (Cervus axis), Dwarf musk deer (Moschus berezovskii), on five species of genus Mazama (Brazilian brocket deer). Total 15 markers were tested on two individuals of each species. Out of these fifteen fourteen were amplified in genus Mazama which was later on confirmed by sequencing (Mantellatto et al., 2010).

\section{Challenges in non-invasive DNA typing}

One of the major challenges in application of DNA technology is in obtaining the genomic DNA from wild populations. It is often not possible to collect blood for DNA isolation specially in natural populations or sometimes in semi-captive areas. Also, for endangered and cryptic species, methods like trapping and radio-collaring may not yield the desired results (Taberlet et al., 1999). Shrinking habitat, less number of individuals, high risk of death or injury during capture for sample collection may also complicate the process (Greenwood, 1996). The methods of non invasive sampling have thus been advocated for field collection of samples, such as collection of fallen hairs, faeces, saliva etc. (Piggott and Taylor, 2003). The potential sources of DNA include shed or plucked hairs from primates, marmots, bear (Constable et al., 2001; Banks et al., 2003). Hair trapping and methods of hair collection for DNA isolation have been proven to be useful in Capuchin monkeys (Valderrama et al., 1999), free ranging black bear and brown bears (Woods et al., 1999). In addition to hairs, the next target for non-invasive sampling can be epithelial cells shed from intestinal lining with faeces (Hoss et al., 1992). DNA isolation from faeces has been effectively used in many wild animal species including primates (Utami et al., 2002), mountain lions (Ernest et al., 2000), bears (Taberlet et al., 1997), dolphins 
(Parsons et al., 1999), black rhinos (Garnier et al., 2001), chital deer (Shrivastava et al., 2013). Besides the faecal DNA other unusual sources of DNA have been also tried like urine in wolves (Valiere and Taberlet, 2000), chewed food in chimpanzees (Morin and Woodruff, 1996), sloughed skins in cetaceans (Valsecchi et al., 1998), nesting materials, egg shells and feathers in birds (Pearce et al., 1997; Nota and Takenaka, 1999). Non invasive genotyping has gained momentum in past decade however, there are some possible limitations that must be considered into. The main limitation is the quality and quantity of DNA obtained from such samples as well as possible contamination of the field samples. This makes microsatellite genotyping error prone. Poor quality DNA or mostly the faecal DNA in microsatellite analysis shows allelic dropouts (mis-identification of heterozygote individual as homozygote) and production of false alleles (Taberlet et al., 1999; Piggott and Taylor, 2003). The error rates are more consistent in faecal DNA, as the quality and quantity of faecal DNA depends on variety of factors, these include time of collection, target species, season of collection, individual variations etc. (Goossens et al., 2000; Shrivastava et al., 2012). For example, Lucchini et al., (2002) have shown that wolf faeces collected in fresh winter produce good quality DNA as compared to the older ones or those collected in summer. Therefore, there are a number of variables affecting quality and quantity of DNA obtained from noninvasive sampling, this however, also implies that a single protocol may not work for all type of samples at all time and DNA isolation protocol needs to be adjusted and developed accordingly (Taberlet et al., 1999).

To nullify the false allele rates, studies using faecal DNA have used replicates of samples per PCR reaction. Initial studies have suggested the use of 10 or more replications per PCR reaction (Navidi et al., 1992), however, it was also found that this multiple tube approach can be effectively used with 3 8 replicates per sample (Taberlet et al., 1999). The other source of error is the contaminating DNA mainly obtained from semi digested food that can produce false bands. To nullify this species specific or genus specific primers can be designed with better sequence homology and stringency (Piggott and Taylor, 2003). If at all, the primer specificity is not reached, the final PCR products can be sequenced to determine their origin and similarity. The other factor to consider is the collection and storage of the samples DNA isolation. The field samples must never be touched with bare hands as human DNA can interfere in analysis, for hairs it is relatively easy to store in paper envelops and bought to lab for processing, however, for faecal DNA utmost care is required, as the type and texture of faeces from each species is different. It is suggested that faecal samples may be dehydrated (Farrell et al., 2000), alcohol treated (Constable et al., 2001), frozen at $-21{ }^{\circ} \mathrm{C}$ (Ernest et al., 2000), or stored in buffers containing high salt concentration (Frantzen et al., 1998) that will hinder the activity of DNA degrading enzymes. A similar consideration is to be given for the extraction protocols. Surface washing and whole sample homogenization can be adopted but they depend on size and type of the faecal matter. Small faecal samples are good for surface wash as some studies (Flagstad et al., 1999) have effectively utilized the surface washing and achieved low error rates (2\%) as compared to whole sample homogenization (30\%). It is clear that type of sample, time of collection, species targeted and contamination are the factors that affect the accuracy of genotyping as well as the collection and DNA extraction protocol that needs to be followed. Therefore, it is imperative to run a pilot study for standardization of collection, storing and extraction protocol before going for large scale field sampling (Taberlet et al., 1999). 
In the current brief review, we tried to underscore the usefulness of microsatellite DNA markers in wildlife conservation and the role it can play in decision making and management of captive mating programms for species conservation. There has been a lot of work that has been done in the field, however, few factors must be considered viz., type of study, species targeted and source and processing of genomic DNA. We also highlighted the advantages that microsatellite provides over other markers viz., being ubiquitous, co-dominant, PCR mediated, hence are preferred for population level studies. Some limitations however still remain, as the requirement of good quality and quantity of DNA, that may instil genotyping error and false alleles, however careful design of experiment and pretesting the protocols using a pilot study will alleviate these difficulties. The use of microsatellite therefore is widespread in wildlife conservation which can be effectively utilized with precautions.

\section{References}

Arif, I.A., Khan, H.A., Shobrak, M., Al Homaidan, A.A., Al Sadoon, M., Al Farhan, A.H. 2010. Measuring the genetic diversity of Arabian Oryx using microsatellite markers: implication for captive breeding. Genes Genet. Syst. 85: 141- 145.

Arora, R., Bhatia, S. 2004. Genetic structure of Muzzafarnagri sheep based on microsatellite analysis. Small Rum. Res. 54: 227-230.

Arranz, J.J., Bayon, Y., San Primitivo, F. 1998. Genetic relationships among Spanish sheep using microsatellites. Anim. Genet. 29: 435-440.

Banks, S.C., Hoyle, S.D., Horsup, A.B., Sunnucks, P., Taylor, A.C. 2003. Demographic monitoring of an entire species by genetic analysis of non- invasively collected material. Animal Conservation. 6:101- 107.

Brinkman, T.J., Person, D.K., Chapin III, F.S., Smith, W., Hundertmarka, K.J. 2011. Estimating abundance of Sitka Black-Tailed deer using DNA from fecal pellets. J. Wildl. Manage. 75(1): 232 242.

Charpentier, M.J.E., Williams, C.V., Drea, C.M. 2008. Inbreeding depression in ring-tailed lemurs (Lemur catta): genetic diversity predicts parasitism, immunocompetence, and survivorship. Conserv Genet. 9(6): 1605 -1615.

Constable, J.L., Ashley, M.V., Goodall J., Pusey, A.E. 2001. Non-invasive paternity assignment in Gombe chimpanzees. Molecular Ecology. 10: 1279 - 1300.

Cosse, M., González, S., Maldonado, J.E. 2007. Cross-amplification tests of ungulate primers in the endangered Neotropical pampas deer (Ozotoceros bezoarticus). Genet. Mol. Res. 6 (4): 1118-1122.

Crnokrak, P., Roff, D.A. 1999. Inbreeding depression in the wild. Heredity. 83: 260270.

DeYoung, R.W., Demarais, S., Gonzales, R.A., Honeycutt, R.L., Gee, K.L. 2002. Multiple paternity in white-tailed deer (Odocoileus virginianus) revealed by DNA microsatellites. Journal of Mammalogy. 83(3): 884-892.

Di Fiore, A., Fleischer, R.C. 2004. Microsatellite markers for woolly monkeys (Lagothrix lagotricha) and their amplification in other New World primates (Primates: Platyrrhini). Molecular Ecology Notes. 4: 246 -249.

Ernest, H.B., Penedo, M.C.T., May, B.P., Syvanen, M., Boyce, W. 2000. Molecular tracking of mountain lions in the Yosemite Valley region in California: genetic analysis using microsatellites and faecal DNA. Molecular Ecology. 9: 433 441. 
Farrell, L.E., Roman, J., Sunquist, M.E. 2000. Dietary separation of sympatric carnivores identified by molecular analysis of scats. Molecular Ecology. 9: $1583-1590$.

Flagstad, O., Roed, K., Stacy, J.E., Jakobsen, K.S. $1999 . \quad$ Reliable noninvasive genotyping based on excremental PCR of nuclear DNA purified with a magnetic bead protocol. Molecular Ecology. 8: 879 -883 .

Frankham, R., Ballou, J.D., Briscoe, D.A. 2002. Introduction to conservation genetics. Cambridge Univ. Press, New York.

Frantzen, M.A.J., Silk, J.B., Ferguson, J.W.H., Wayne, R.K., Kohn, M.H. 1998. Empirical evaluation of preservation methods for faecal DNA. Molecular Ecology. 7: 1423 - 1428.

Garnier, J.N., Bruford, M.W., Goossens, B. 2001. Mating system and reproductive skew in the black rhinoceros. Molecular Ecology. 10: 2031- 2041.

Goossens, B., Chikhi, L., Utami, S.S., de Ruiter, J., Bruford, M.W. 2000. A multisamples, multi-extracts approach for microsatellite analysis of faecal samples in an aboreal ape. Conservation Genetics. 1: $157-162$.

Greenwood, J.J.D. 1996. Basic Techniques. In 'Ecological Census Techniques, a Handbook'. (Ed.) W.J. Sutherland. Cambridge University press, Cambridge. Pp. 11-110.

Haanes, H., Rosef, O., Veiberg, V., Røed, K.H. 2005. Microsatellites with variation and heredity applicable to genetic studies of Norwegian red deer (Cervus elaphusatlanticus). Anim Genet. 36(5): 454-455.

Hoss, M., Kohn, M., Paabo, S., Knauer, F., Schroder, W. 1992. Excrement analysis by PCR. Nature. $359: 199$.

Inoue, E., Inoue-Murayama, M., Takenaka, O., Nishida, T. 2007. Wild chimpanzee infant urine and saliva sampled noninvasively usable for DNA analyses. Primates. 48(2) : 156-159.

Jarne, P., Lagoda, P.J.L. 1996. Microsatellites, from molecules to populations and back. Trends Ecol. Evol. 11: 424 - 429.

Knapik, E. W., Goodman, A., Ekker, M., Chevrette, M., Delgado, J., Neuhauss, S., Shimoda, N., Driever, W., Fishman, M.C., Jacob, H.J. 1998. A microsatellite genetic linkage map for zebrafish (Danio rerio). Nat. Genet. 18: 338 - 343.

Li, K., Geng, J., Qu, J., Zhang, Y., Hu, S. 2010. Effectiveness of 10 polymorphic microsatellite markers for parentage and pedigree analysis in plateau pika (Ochotona curzoniae). BMC Genetics. 11:101.

Li, K., Geng, J., Yang, J., Zhang, Y., Hu, S. 2009. Isolation and characterization of 13 microsatellite loci in the plateau pika (Ochotona curzoniae). Conservation Genetics. 10(3):785-787.

Liberg, O., Andren, H., Pedersen, H., Sand, H., Sejberg, D., Wabakken, P., Akesson, M., Bensch. S. 2005. Severe inbreeding depression in a wild wolf (Canis lupus) population. Biol. Lett. 1: 17-20.

Litt, M., Lutty, J.A. 1989. A hypervariable microsatellite revealed by in vitro amplification of a dinucleotide repeats within the cardiac muscle actin gene. Am. J. Human Genetics. 44: 397-401.

Lucchini, V., Fabbri, E., Marucco, F., Ricci, S., Biotani, L., Randi, E. 2002. Noninvasive molecular tracking of colonising wolf (Canis lupus) packs in the Western Italian Alps. Molecular Ecology. 11: $857-868$.

Luikart, G., Biju-Duval, M.P., Ertugrul, O., Zagdsuren, Y., Maudet, C., Taberlet, P. 1999. Power of 22 microsatellite markers in fluorescent multiplexes for parentage testing in goats (Capra hircus). Anim Genet. 30: 431-438. 
Luty, J.A., Guo, Z., Willard, H.F., Ledbetter, D.H., Ledbetter, S., Litt, M. (1990). Five polymorphic microsatellite VNTRs on the human X chromosome. Am. J. Hum. Genet. 46: 776-783.

Mantellatto, A.M.B., Carnelossi, E.A.G., Duarte, J.M.B. 2010. Transferability of microsatellite loci from exotic Cervidae to Brazilian brocket deer (Mazama spp, Mammalia: Cervidae). Genetics and Molecular Research. 9 (1): 277-282.

Mateus, J.C., Penedo, M.C., Alves, V.C., Ramos, M., Rangel-Figueiredo, T. 2004. Genetic diversity and differentiation in Portuguese cattle breeds using microsatellites. Anim. Genet. 35:106113.

Maudet, C., Luikart, G., Taberlet, P. 2002. Genetic diversity and assignment tests among seven French cattle breeds based on microsatellite DNA analysis. J. Anim. Sci. 80: 942-950.

Morin, P.A., Woodruff, D.S. 1996. Noninvasive genotyping for vertebrate conservation. In 'Molecular Genetic Approaches in Conservation'. (Eds.) T.B. Smith, R.K. Wayne. Oxford university press, New York. Pp. $298-313$.

Navidi, W., Arnheim, N., Waterman, M.S. 1992. A multiple tube approach for accurate genotyping of very small DNA samples by using PCR: statistical considerations. American Journal of Human Development. 50: 347 - 359.

Nguyen, T.T., Genini, S., Bui, L.C., Voegeli, P., Stranzinger, G., Renard, J., Maillard, J., Nguyen, B.X. 2007. Genomic conservation of cattle microsatellite loci in wild gaur (Bos gaurus) and current genetic status of this species in Vietnam. BMC Genetics. 8:77.

Nota, Y., Takenaka, O. 1999. DNA extraction from urine and sex identification of birds. Molecular Ecology. 8: 1235 - 1238.

O'Grady, J., Broofe, B.W., Reed, D.H., Ballon, J.D., Tonkyn, D.W., Frankham,
R. 2006. Realistic levels of inbreeding depression strongly affect extinction risk in wild populations. Biological Conservation. 133: 42-51.

Parsons, K.M., Dallas, J.F., Claridge, D.E., Durban, J.W., Balcomb, K.C., Thompson, P.M., Noble, L.R. 1999. Amplifying dolphin mitochondrial DNA from faecal plumes. Molecular Ecology. 8: $1753-1768$.

Pearce, J.M., Fields, R.L., Scribner, K.T. 1997. Nest materials as a source of genetic data for avian ecological studies. Journal of Field Ornithology. 68: 471481.

Piggott, M.P., Taylor, A.C. 2003. Remote collection of animal DNA and its application in conservation management and understanding the population biology of rare and cryptic species. Wildlife Research. 30: 1-13.

Ralls, K., Ballou, J.D., Templeton, A. 1988. Estimates of lethal equivalents and the cost of inbreeding in mammals. Conservation Biology. 2: 185- 193.

Ruiz-Garcia, M., Payan, E., Murillo, A., Alvarez, D. 2006. DNA microsatellite characterization of the jaguar (Panthera onca) in Colombia. Genes Genet. Syst. 81: 115-127.

Russello, M.A., Amato, G. 2004. Ex- situ population management in the absence of pedigree information. Mol. Ecol. 13: 2829-2840.

Saccheri, I., Kuussaari, M., Kankare, M., Vikman, P., Fortelius, W., Hanski, I. 1998. Inbreeding and extinction in a butterfly metapopulation. Nature. 392: 491-494.

Shrivastava K., Thakur, M.S., Parmar, S.N.S., Shrivastav, A.B. 2013. Microsatellite characterization of Chital deer (Axis axis) by using faecal DNA. Vet. World. 6(2): 83-86.

Shrivastava, K., Parmar, S.N.S., Shrivastav, A.B. 2012. Faeces as a source of DNA 
for wildlife conservation: a brief perspective. Life Science Bulletin. 9(1): $52-54$.

Slate, J., Kruuk, L.E.B., Marshall, T.C., Pemberton, J.M., Clutton-Brock, T.H. 2000. Inbreeding depression influences lifetime breeding success in a wild population of red deer (Cervus elaphus). Proc. R. Soc. Lond. B. 267: 1657-1662.

Slate, J., Pemberton, J.M. 2002. Comparing molecular measures for detecting inbreeding depression. J. Evol . Biol. 15:20-31.

Taberlet, P., Camarra, J.J., Griffin, S., Uhres, E., Hanotte, O., Waits, L.P., DuboisPaganon, C., Burke, T., Bouvet, J. 1997. Noninvasive genetic tracking of the endangered Pyrenean brown bear population. Molecular Ecology. 6: 869 876.

Taberlet, P., Waits, L.P., Luikart, G. 1999. Non-invasive genetic sampling: look before you leap. Trends in Ecology and Evolution. 14: 323-327.

Utami, S.S., Goossens, B., Bruford, M.W., de Ruiter, J., van Hoof, J.A.R.A.M. 2002. Male bimaturism and reproductive success in Sumatran orangutans. Behavioral Ecology. 13: 643-652.

Valderrama, X., Karesh, W.B., Wildman, D.E., Melnick, D.J. 1999. Noninvasive method for collecting fresh hair tissue. Molecular Ecology. 8: 1749 - 1752. Valiere, N., Taberlet, P. 2000. Urine collected in the field as a source of DNA for species and individual identification. Molecular Ecology. 9: 2149 -2154.

Valsecchi, E., Glockner-Ferrari, D., Amos, W. 1998. Molecular analysis of the efficiency of sloughed skin sampling in whale population genetics. Molecular Ecology. 7: 1419 - 1422.

Valvo, G., Sturaro, E., Maretto, F., Ramanzin, M. 2009. Genetic analysis reveals Roe deer (Capreoluscapreolus) population structure in North-Eastern Italian Alps. Ital. J. Anim. Sci. 8 (3): 104-106.

Wimmer, B., Tautz, D., Kappeler, P.M. 2002. The genetic population structure of the grey mouse lemur Microcebus murinus, a basal primate from Madagascar. Behav. Ecol. Sociobiol. 52: 166-175.

Woods, J.G., Paetkau, D., Lewis, D., McLellan, B.N., Proctor, M., Strobeck, C. 1999. Genetic tagging of free ranging black and brown bears. Wildlife Society Bulletin. 27: 616 - 627.

Zidek, R., Pokorádi, J., Bandry, L. 2008. Biodiversity in deer population observed by microsatellite markers. Journal of Agrobiology. 25: 113-115.

Zsolnai, A., Lehoczky, I., Gyurmán, A., Nagy, J., Sugár, L., Anton, I., Horn, P., Magyary, I. 2009. Development of eightplex microsatellite PCR for parentage control in deer. Archiv Tierzucht. 52(2): 143-149.

\section{How to cite this article:}

Kush Shrivastava, Rebeka Sinha, Shweta Singh Chauhan, Mohan Singh Thakur 2018. Microsatellite Markers in Conservation and Management of Wildlife: a Brief Perspective Int.J.Curr.Microbiol.App.Sci. 7(07): 2274-2282. doi: https://doi.org/10.20546/ijcmas.2018.707.265 